This item was submitted to Loughborough's Research Repository by the author.

Items in Figshare are protected by copyright, with all rights reserved, unless otherwise indicated.

\title{
Concurrent and prospective associations among biological maturation, and physical activity at 11 and 13 years of age
}

PLEASE CITE THE PUBLISHED VERSION

http://dx.doi.org/10.1111/sms.12103

\section{VERSION}

AM (Accepted Manuscript)

\section{PUBLISHER STATEMENT}

This work is made available according to the conditions of the Creative Commons Attribution-NonCommercialNoDerivatives 4.0 International (CC BY-NC-ND 4.0) licence. Full details of this licence are available at: https://creativecommons.org/licenses/by-nc-nd/4.0/

\section{LICENCE}

CC BY-NC-ND 4.0

\section{REPOSITORY RECORD}

Cumming, Sean P., Christopher J. Riddoch, Lauren B. Sherar, Dale W. Esliger, and Robert M. Malina. 2019. "Concurrent and Prospective Associations Among Biological Maturation, and Physical Activity at 11 and 13 Years of Age". figshare. https://hdl.handle.net/2134/22575. 
Concurrent and Prospective Associations among Biological Maturation, and Physical Activity at 11 and 13 Years of Age.

\author{
Sean P. Cumming1 \\ Lauren B. Sherar2 \\ Dale W. Esliger2 \\ Chris J. Riddoch1 \\ Robert M. Malina3
}

1 Department for Health, University of Bath, Bath, UK

2 School of Sport, Exercise \& Health, Loughborough University, Loughborough, UK 3 Tarleton State University and University of Texas at Austin, TX, USA

Dr. Sean P. Cumming

1.10 Eastwood Offices 20/21

University of Bath

Bath, UK

BA2 7AY

s.cumming@bath.ac.uk

Running Head: Biological Maturation and Physical Activity Key Words: Puberty; Adolescence; Exercise; Timing; Adiposity, ALSPAC 


\begin{abstract}
This study examined concurrent and prospective associations between objective measures of biological maturation, body composition and physical activity (PA) in adolescent males ( $n=671$ ) and females ( $n=680)$. Participants born to women recruited to the Avon Longitudinal Study of Parents and Children birth cohort study were assessed at 11 and 13 years. Percentage of predicted adult stature was used as an estimate of biological maturation. PA and time sedentary was assessed over 7 consecutive days using Actigraph accelerometers. Body composition was assessed using whole body DXA scans. At 11 and 13 years, maturity in males was inversely associated with accelerometer counts-per-minute (CPM) and time engaged in light PA, and positively associated with time sedentary. In females, maturity was inversely associated with accelerometer (CPM) at 11 but not 13 years. Adjusting for accelerometer wear times and corresponding activity levels at 11 years, maturity and percentage fat-mass at 11 years did not predict any indices of PA or sedentary behavior in males or females at 13 years. Whereas advanced maturation in males is associated with less PA and more sedentary behaviour at 11 and 13 years, maturity at 11 does not predict PA or sedentary behaviour at 13 years in either sex.
\end{abstract}


Regular participation in physical activity (PA) is a prerequisite for healthy physical and psychological development. Individuals who regularly engage in moderate-to-vigorous physical activity (MVPA) demonstrate enhanced functional capacity (e.g., strength, speed, power, aerobic and anaerobic capacity) and have better cardiometabolic and behavioural health (Cumming \& Riddoch 2009). The benefits associated with an active lifestyle begin at a relatively early age. Nevertheless, children have become increasingly less active across many domains, including physical education, active transport (e.g., walking, cycling), and leisure-time activities (Dollman et al. 2005).

PA gradually declines as the individual progresses towards the mature state, i.e. adulthood. This trend has been consistently documented across cultures and in many animal species, and suggests a biological basis to PA (Eisenmann \& Wickel 2009). In support of this contention, advanced biological maturation in girls has repeatedly been show to explain why girls are less active when compared to boys of the same chronological age (Sherar et al. 2010). In humans, the decline in PA begins in late childhood, continues through adolescence, and is especially noticeable in the form of active play, a behaviour that plays an important role in psychosocial development and is associated with the development of the cerebellum, i.e., synaptic pruning and myelination (Byers 1998). Changes in the sensitivity and release of the dopamine system have also been advanced as potential mechanisms underlying the maturity associated decline in PA (Eisenmann \& Wickel 2009).

The impact of maturity timing (i.e., whether one is maturationally advanced, on time, or delayed) upon PA within sex remains unclear (Sherar et al. 2010). Children of the same chronological age vary considerably in biological maturity. Skeletal age can vary by 4 to 5 years among children 7 or 8 years of age, while the timing of maximum growth in height (peak height velocity) in longitudinal samples of boys can range from 11 to 17 years. Similar variation is apparent in pubertal maturation. Some youth pass from the prepubertal to the 
mature state in two years while the process can take up to 5 or more years in others (Malina et al. 2004). Understanding how variance in the timing of maturity does, or does not, impact adolescent engagement in PA may help health practitioners better identify individuals who are in need of support and more effectively tailor PA interventions

The timing and tempo of maturation has important consequences for physical and psychobehavioral development, some of which may impact involvement in PA (Cumming et al. 2012). In adolescent females, the physical characteristics associated with advanced maturation (i.e., greater pubertal gains in height, weight, weight-for-height, and absolute and proportional fat-mass) are considered less conducive to successful engagement in many forms of PA, especially those that require weight bearing, aesthetics, or endurance. Early maturing girls also socialize with older peers (Caspi \& Moffitt 1991), who tend to be less active. Maturity timing may also indirectly influence girls involvement in PA, through more negative perceptions and beliefs regarding the physical self (body image. physical selfconcept, values regarding maturation and PA) or the reactions and evaluations of others (e.g., peers, parents, educators) (Cumming et al. 2012). Accordingly, an inverse relation between maturity timing and PA is predicted in girls (Sheraret al. 2010).

Whereas early maturing boys might be expected to be less active than their peers (based on the observation that PA generally declines as individuals progress towards the mature state), the physical and functional characteristics associated with advanced maturity in males (i.e., greater physical size and absolute and relative fat free mass, superior strength, power, and speed) are more conducive to successful engagement in many popular forms of structured PA (e.g., competitive sports). Thus, a general declines in PA associated with advanced maturity might be offset by greater involvement in more vigorous and structured activities such as sports. It is not clear, however, if it is advanced maturity, per se, that predisposes many boys to competitive sports or the cultural socialization of boys advanced in 
maturity status into competitive sports. Accordingly, researchers should examine how relations between maturation and PA might vary relative to different activity type (e.g., exercise, sport) and/or intensities (moderate to vigorous, light).

Studies investigating the impact of maturity timing on adolescent PA have yielded equivocal results. Whereas several studies have found early maturing females to be less active (Cumminget al. 2008; Cumming et al. 2011; Davison et al. 2007; Hearst et al. 2012; Hunter Smart et al. 2012; Riddoch et al. 2007), an equivalent number have observed no effect of maturity timing (Gebremariam et al. 2012; Niven et al. 2007; Sherar et al. 2009; Wickel \& Eisenmann 2007; Zitouni \& Guinhouya 2012), or, in one study, early maturing girls to be more active (van Jaarsveld et al. 2007). Corresponding data for males is limited and even less conclusive. Whereas, most studies have observed no relation between timing and PA (Bradley et al. 2000; Gebremariamet al. 2012; Hearstet al. 2012; Riddochet al. 2007; Wickel \& Eisenmann 2007), two studies found early maturing boys to be less active (Romon et al. 2004; Zitouni \& Guinhouya 2012) while another study found the opposite effect (van Jaarsveldet al. 2007).

The inconsistent findings related to maturity timing and PA have been attributed to numerous factors including; (1) lack of objective measures of both maturity and PA; (2) inconsistent methods for classifying individuals as early, on time, or late; (3) limited consideration of mediating and moderating factors; (4) small samples sizes; (5) the failure to consider the simultaneous effects of body composition (i.e., fat mass, fat free mass); and (6) the potential for diminishing effects of maturation with age (Cumming et al. 2012; Sheraret al. 2010). To better understand how the processes of growth and maturation contribute to health behaviours and outcomes in youth, it has also been recommended that researchers study samples of children of the same chronological age, yet who vary in biological maturation (Katzmarzyk et al. 2012). With these suggestions in mind, the purpose of this 
study was to use objective measures to examine concurrent (i.e., cross-sectional) and prospective (i.e., longitudinal) associations between biological maturity, body composition and PA, in a large contemporary cohort of British youth at 11 and 13 years of age. In accordance with the contentions of Sherar et al., (2010) it was hypothesised that in males and females, advanced biological maturity at 11 years of age would be associated with less PA, yet more sedentary behaviour, at 11 and 13 years.

Materials and Methods

\section{Participants}

Participants were members of the Avon Longitudinal Study of Parents and Children (ALSPAC) birth cohort study and residents of the former county of Avon in the southwest of England. ALSPAC, also known as the Children of the 90's study involved more than 14,000 mothers who enrolled during pregnancy in 1991 and 1992. Data was collected from the mothers and fathers prior to the birth of the children and the health and development of the children has been followed in detail since birth. The study was approved by the ALSPAC Law and Ethics Committee and other local ethics committees. The data included in the present study was collected at two time points, the first occurring between January 2003 and January 2005, when the participants were 11 years old. The second time point occurred two years later when the participants were 13 years old. Participants who were assessed at 11 and 13 years of age with complete data at each time point were included in this study.

\section{Assessments}

Biological Maturation. Percentage of predicted mature (adult) height attained at measurement was used as an objective indicator of biological maturation. The method assumes that among children of the same chronological age, the child that is closer to his or her predicted mature height is more advanced in biological maturity (Malina et al. 2004). For example, a girl who has attained 95\% of her predicted adult height at 12 years is considered 
biologically more mature than a girl of the same age who has attained $85 \%$ of her predicted adult height.

The Khamis-Roche method (Khamis \& Roche 1994) was employed to predict mature height from current age, height and weight of the participant, and mid-parent height (i.e., average height of biological parents) (Figure 1). Although this method was originally derived from data collected in the United States, British and American boys and girls, aged 9-15 years, present very similar growth trajectories and mean values for height and weight (Cole 1994). The mean (median absolute deviation) and 90\% error bounds between actual and predicted mature height from 4 to 18 years of age, are $2.2 \mathrm{~cm}$ and $5.3 \mathrm{~cm}$ in males, and 1.7 cm and $4.3 \mathrm{~cm}$ in females, respectively (Khamis \& Roche 1994). Intra-class correlations between the predicted adult stature at 11 and 13 years of age were .95 for males and .89 for females.

Heights of the biological parents were self-reported as part of separate mother and biological partner questionnaires administered 12 weeks into the gestation process Selfreported height is a valid and accurate approximation of true height whether self-reported or reported by a spouse (Himes \& Roche 1982), and is highly correlated with actual height ( $r$ ranges from .93 to .99) (Hensley 1998). Although associated biases and errors in self-reports of height are considered small and non-consequential (Palta et al. 1982), values were adjusted for over-estimation using sex specific equations (Figure 2) constructed from over 1000 measured and estimated heights of adults (Epstein et al. 1995).

Percentage of mature stature has been used as an index of biological maturation in a studies involving US, and British youth (Malina et al. 2005; Malina et al. 2006) and has been validated against established indicators of maturity (skeletal age) in US youth (Malina et al. 2007). It has also demonstrated concurrent validity in British (Cumminget al. 2011; Smart et al. 2012) samples. 
Anthropometric variables. Participants' heights were assessed with socks and shoes removed using a Harpenden stadiometer. A Tanita TBF 305 weighing scale was used to assess body mass. Body Mass Index (weight/height; $\mathrm{kg} / \mathrm{m}^{2}$ ) was calculated. Body composition was measured using a Lunar Prodigy DXA scanner (GE Medical Systems Lunar, Madison, WI, USA). Scans (fast mode) were manually screened for anomalies, motion and material artefacts. The edges and nodes for the various sub regions were manually aligned in accordance with criteria based on bony anatomical landmarks. Components of body composition included in the current study were total body fat mass, trunk fat mass, and lean mass.

Physical activity and sedentary time. Participants attending the research clinics at 11 and 13 years of age were asked to wear an Actigraph 7164 accelerometer (Actigraph LLC, Pensacola, FL, USA) for seven days. The accelerometer was worn on a belt that fastened around the waist, with the monitor resting at mid-clavicular line. Participants were instructed to wear the accelerometer during waking hours and remove the device when bathing, showering or engaging in any water based activities. Consistent with inclusion criteria employed and described in previous studies involving the ALSPAC cohort (cf. Riddoch et al. 2009), participants had to have worn the accelerometer, at age 11 and 13, for a minimum of 10 hours on at least three days (following the deletion of monitor non-wear), one of which had to be a weekend day. Non-wear was defined as all periods of $>10$ consecutive minutes of zero.

Accelerometer physical activity was expressed as average counts-per-minute (CPM) and average minutes spent daily in moderate-to-vigorous physical activity (MVPA; >3600 CPM), LPA (>2000 \& <3600 CPM) and sedentary (<199). The intensity thresholds were derived from a previous calibration study (Mattocks et al. 2007) and consistent with the criteria used in previous ALSPAC studies (c.f., Riddoch et al., 2009). 
Please note that the study website contains details of all the data that is available through a fully searchable data dictionary (http://www.bris.ac.uk/alspac/researchers/dataaccess/data-dictionary/)

Statistics. Descriptive statistics were calculated for growth and maturation characteristics, counts per minute, and time spent sedentary and in MVPA and LPA. Pearson product moment correlations (one-tailed) were used to examine concurrent relations among biological maturation and the variables of interest (e.g., physical activity, sedentary behavior, body size and composition). Partial correlations, controlling for the mean daily monitor wear time, were calculated for all concurrent associations between maturation and time sedentary and in MVPA and LPA. Multilevel (i.e., hierarchical linear) modeling, using maximum likelihood estimation, examined predictive relations of biological maturation, body composition, and PA at 11 years of age, upon the various indices of PA at age 13.

\section{Results}

\section{Descriptive statistics}

Descriptive statistics for chronological age, biological maturation, body size, body composition, and PA are presented by age and sex in Table 1. The mean values of percentage of predicted adult stature are marginally higher than corresponding values for British youth at 11.5 (males 82.2\%; females $89.8 \%$ ) and 13.5 years of age (males $89.4 \%$; females 96.3\%) derived from existing data (Child Growth Foundation 2005). It should be noted, however, that the mean ages for male and female participants at each assessment (11.7 and 13.8 years) were slightly above 11.5 and 13.5 years. In males, mean values for height, weight and BMI approximated the $75 \mathrm{th}^{\text {th }}$ centiles for 11.5 and 13.5 years of age. In females, mean values for height fell between the $50^{\text {th }}$ and 75 th $^{\text {th }}$ centiles for 11.5 and 13.5 years of age; whereas mean values for weight and BMI approximated the $75^{\text {th }}$ centiles for each age. The greater values for body size may reflect secular changes in the size of British youth and/or the 
marginally older mean chronological age values observed in our sample. The growth reference data used in the current study were derived from data collected from British youth in 1990.

\section{Correlations}

Correlates of biological maturity are presented by sex and age in Table 2. Biological maturation was inversely associated with mean CPM at 11 and 13 years and on weekdays and weekends in males. Advanced maturity in males was associated with lower MVPA at 11 years (weekdays and weekends), but not 13 years. Advanced maturity in males was associated with less LPA and more sedentary time at 11 and 13 years of age. In females, maturation was inversely associated with mean CPM at 11, but not 13 years in females. The magnitude of the association between maturation and overall PA at age 11, though small, was also observed for weekdays and weekends. Contrary to expectations, biological maturation was unrelated to MVPA, LPA, and time sedentary at 11 and 13 years.

\section{Multilevel models}

A series of multilevel models were generated to examine the predictive associations of biological maturation and body composition at 11 years, upon the indices of PA and sedentary behavior at age 13. In each model physical activity included weekdays and weekend days, and separate models were generated for males and females. Biological maturation and percentage total body fat at age 11 were entered as fixed factors in all models. To control for potential confounding effects, the following variables at 11 years of age were included as fixed factors in the models and when predicting physical activity at 13 years: monitor wear time, mean CPM or minutes spent sedentary, in MVPA or LPA (dependent upon the corresponding outcome measure).

In accordance with procedures described by Field (2005), fixed effects models were initially tested (Model 1). Following evaluation of the baseline models, the intercepts were 
then allowed to vary across the individual participants (Model 2). Finally, the slopes describing the relation between biological maturation and the various indices of physical activity at 13 were allowed to vary across individuals (Model 3). Model modifications that did not significantly improve model fit were rejected. All models were considered final when further modifications did not result in improved fit. Coefficients, standard errors and confidence associated with each of the final models are presented for males and females in Tables 3 and 4, respectively.

Multilevel models predicting mean accelerometer CPM at 13 years.

In males, mean accelerometer CPM at age 11 was the single significant predictor of mean CPM at age 13, $\mathrm{F}(1,671)=166.3, \mathrm{p}<.001$, in Model 1 . Allowing the intercepts to vary across participants (Model 2) resulted in a significant improvement in model fit, $\Delta \chi^{2}(1)=$ 4.0, $\mathrm{p}<.05$; however, mean CPM at $11, \mathrm{~F}(1,693.5)=169.3, \mathrm{p}<.001$, remained as the only significant predictor. Allowing the slope representing the relation between biological maturation and overall PA at 13 to vary across individuals did not result in improved model fit. As with the males, mean CPM at 11 was the only significant predictor of mean CPM at 13 in females, $\mathrm{F}(1,680)=122.6, \mathrm{p}<.001$ ( Model 1). Allowing the intercepts to vary across individual participants (Model 2) did not result in improved model fit. Similarly, allowing the slope between biological maturation and overall physical activity at 13 to vary across individuals (Model 3) did not improve model fit.

Multilevel models predicting mean daily minutes of MVPA at 13 years.

For the models predicting variance in accumulated physical activity at various intensities, mean monitor wear times at age 11 and 13 years were included in the model as control variables, as was the mean number of minutes engaged in the physical activity at the respective intensity at age 11 . In males, monitor wear time at age $11, \mathrm{~F}(1,671)=9.8, \mathrm{p}<.01$, and at age 13, $\mathrm{F}(1,671)=39.8, \mathrm{p}<.001$, and MVPA at 11, $\mathrm{F}(1,671)=142.5, \mathrm{p}<.001$, 
significantly predicted MVPA at 13. Although, allowing the intercepts to vary across individuals resulted in improved model fit $\Delta \chi 2(1)=5.0, \mathrm{p}<.05$; wear time at age 11, $\mathrm{F}(1,482.2)=11.5, \mathrm{p}<.01$, and at age 13, $\mathrm{F}(1,608.7)=42.3, \mathrm{p}<.001$, and MVPA at 11, $\mathrm{F}(1,653.0)=148.1, \mathrm{p}<.001$, remained as the only significant predictors. Permitting the slope between biological maturation and MVPA to vary did not result in improved model fit. In the baseline model for females (Model 1), wear time at age 13, $F(1,680)=24.5, p<.001$, and MVPA at age $11, \mathrm{~F}(1,680)=116.5, \mathrm{p}<.001$, were significant predictors of MVPA at age 13 . Subsequent modifications to the baseline model (i.e., allowing the intercepts/slopes to vary across individuals) failed to generate improvements in model fit.

Multilevel models predicting mean daily minutes of LPA at 13 years.

In the baseline model predicting the mean number of minutes (per-day) males engaged in LPA at age 13, accelerometer wear time at $11, \mathrm{~F}(1,671)=26.6, \mathrm{p}<.001$, and 13 years, $\mathrm{F}(1,671)=110.5, \mathrm{p}<.001$, and LPA at age $11, \mathrm{~F}(1,671)=205.1, \mathrm{p}<.001$ were significant predictors. Allowing the intercepts (Model 2), and slope between biological maturation at 11 and time spent in LPA at 13 (Model 3), to vary across individuals did not significantly improve model fit. Testing the same model in females, accelerometer wear time at ages $11, \mathrm{~F}(1,680)=19.5, \mathrm{p}<.001$, and 13 years, $\mathrm{F}(1,680)=87.0, \mathrm{p}<.001$, and LPA at age $11, \mathrm{~F}(1,680)=197.9, \mathrm{p}<.001$, acted as significant predictors of minutes spent LPA, per day, at age 13. As with males, further modifications to the model for females did not result in improved fit.

Multilevel models predicting mean daily minutes sedentary at 13 years.

For the models predicting mean number of minutes, per day, that males engaged in sedentary activity at age 13 , accelerometer wear time at $11, \mathrm{~F}(1,671)=22.2, \mathrm{p}<.001$, and 13 years of age, $\mathrm{F}(1,671)=207.5, \mathrm{p}<.001$, and mean minutes engaged daily in sedentary activity at age $11, \mathrm{~F}(1,671)=211.6, \mathrm{p}<.001$, were significant predictors (Model 1). 
Allowing the intercepts (Model 2), and slope between biological maturation at 11 and sedentary time at 13 (Model 3), to vary across individuals did not significantly improve model fit. In the baseline model for females, accelerometer wear time at ages $11, \mathrm{~F}(1,680)=$ 29.2, $\mathrm{p}<.001$, and 13 years, $\mathrm{F}(1,680)=380.6, \mathrm{p}<.001$, and time spent sedentary at age 11 , $F(1,680)=200.9, p<.001$, were significant predictors of mean time spent sedentary at 13 years. As with males, subsequent modifications to the model did not result in improved fit.

\section{Discussion}

Concurrent and prospective associations between biological maturation, body composition, and objective measures of physical activity were evaluated in a large cohort of British youth at two time points. The results supported concurrent associations between biological maturation, PA, and sedentary behavior in males but not females. No evidence of prospective associations between biological maturation and the variables of interest (i.e., PA and time spent sedentary) were observed in either sex.

At 11 and 13 years of age, advanced biological maturation in males was associated with less CPM, less time spent in LPA, and greater time sedentary. Advanced maturation was also associated with less time engaged in MVPA at age 11, but not at 13. The absence of an association at 13years of age may reflect the greater involvement of early maturing males in activities such as competitive sports, potentially offsetting any maturity-associated decline in more general forms of MVPA. The bias towards selection early maturing males in many sports has been shown to become more pronounced with age during adolescence (Malina 2011). That said, the general findings suggest that advanced maturation in males is associated with less activity during late childhood and early adolescence, and are consistent with observations on French boys, among whom advanced maturation was associated with lower daily pedometer step counts and less time spent engaged in MVPA (Romon et al. 2004; Zitouni \& Guinhouya 2012). 
Corresponding associations between biological maturation and PA and sedentary behavior in females were less conclusive. Advanced maturation was associated with less mean CPM at 11, but not, 13 years. Though significant, the magnitude of the association at 11 was small and, thus, this result should be considered with caution. The absence of an association between maturation and CPM at 13 suggests that the effects of maturity timing on PA in adolescent females might be transient. It is possible that the association observed at age 11 may be more closely related to the process of entering puberty than the effects of maturity timing, per se. The onset of puberty brings many physical and psychosocial changes, some of which may make it difficult for girls to continue engaging in some forms of PA, especially activities that may be considered socially or culturally less acceptable. This may explain why maturity was unrelated to CPM at 13 years, i.e., the majority of girls would have entered puberty by this age. Contrary to expectations, maturation in females was unrelated to time spent sedentary or in MVPA and LPA, at 11 and 13 years of age. Collectively, the results suggest that the effects of maturity upon PA and sedentary behaviors in adolescent girls may be less than previously suggested.

The concurrent associations between maturation and measures of body composition are also of interest. At 11 years, advanced maturation in males was associated with a greater percentage of total body fat mass (and by inference a lower percentage of total body lean mass) and with a greater percentage of fat mass on the trunk. However, at 13 years, maturity status was unrelated to the indicators of relative body composition. This may reflect the differential changes in body composition associated with the growth spurt in males. Percentage fat mass tends to decline during male adolescence due to the rapid growth of lean mass, specifically muscle mass (Malina et al., 2004). At 11 and 13 years, advanced maturity in females was associated with a higher percentage of total body and trunk fat mass, and by inference a lower percentage of total body lean mass. The consistency of these associations 
reflects girls earlier entry into puberty ( 2 years) and pubertal increases in absolute and relative fat mass (Malina et al., 2004).

The models examining prospective associations among maturity, body composition, and PA should also be considered. Contrary to expectations, biological maturation and percentage of total body fat at 11 years were unrelated to all indices of PA and sedentary behaviors at age 13 (i.e. CPM, time sedentary \& time in MVPA \& LPA). In a similar study, Knowles et al., (2009) reported that maturity and physical characteristics of Scottish girls aged 11 to 12 years did not predict changes in PA over a 12 month period. Collectively, these results suggest that maturity status and percentage fat mass have limited bearing upon future engagement in PA. It should be noted, however, that, the corresponding measure of PA or sedentary behavior at 11 years served as consistent predictors of the equivalent outcomes at 13 years. This suggests that individual differences in PA and sedentary behaviors are reasonably stable between the 11 and 13 , and that the best predictor of future involvement in PA and sedentary behavior is past behavior.

The results of the current study suggest that the effects of maturation on PA and sedentary behavior are weaker or more complex than previously assumed. Emerging evidence in females suggests that maturity associated differences in PA and physical selfconcept (a documented mediator of the association between maturation and PA in adolescent females) may be most evident at the extremes of the maturity continuum (i.e., most vs. least mature girls), and that being slightly advanced on delayed in maturity has limited bearing on health related behaviors or outcomes (Cumming et al. 2012). The effects of maturation on the health related behaviors and outcomes in adolescents might also vary relative to the sociocultural environment, with negative outcomes associated with early maturation being accentuated in adverse social contexts (Ge et al. 2011). This phenomenon, referred to as the 'Context Amplification Hypothesis', has been supported in regard to a number of health 
related behaviors and outcomes (Geet al. 2011), including PA. Pindus et al., (2012) reported that high perceptions of peer support mitigated the negative effects of early maturation on PA in adolescent females. Positive socioeconomic or family contexts might also mitigate any negative effects of advanced maturity on PA or sedentary behavior. Sociocultural differences and secular trends relating to children and adolescents’ interests and opportunities may further complicate association between maturity timing and PA/sedentary behavior. For example, marked increases in computer use during mid-adolescence have been documented in boys and girls between 1999 and 2005 (Nelson et al. 2006).

Although the current investigation has a number of strengths (e.g., large sample, objective measures), it is not without limitations. This study did not control for psychological factors that could mediate relations between maturity and PA (Sheraret al. 2010). Perceptions of the self have been shown to mediate relations between maturity and PA in females, with negative perceptions attractiveness, fitness, and sports competence and explaining why early maturing females tend to be less active (Cumming et al. 2012). The ages at which the participants were assessed also represent different stages of puberty and the growth spurt, in girls and boys. Many of the girls in the current study were likely pubertal and in the midst of their growth spurts at the first observation and sexually mature at the second observation. In contrast, fewer of the boys would have been in early puberty and/or at take-off of the growth spurt in height at the first observation, and in the interval of maximum growth rate in height (peak height velocity) at the second observation. As noted, the effects of maturity on PA might vary relative to pubertal stage or the growth spurt.

The findings of this study are also limited to British youth aged between 11 and 13 years. The effects of maturation status on health behaviors and outcomes might vary relative to age or culture. The time span between the two assessments was also relatively short and, thus, does not provide a comprehensive representation of puberty or adolescence. The effects 
of body composition or maturation status in early adolescence upon health behaviors might not be realized until late adolescence (e.g., ages 15 to 17). Accordingly, future studies should adopt an interdisciplinary approach examining the developmental trajectories of maturity associated variance in health behaviors and outcomes over a longer period, ideally from late childhood (i.e., ages 9-10 years) to early adulthood (i.e., 18-20 years). Further, such studies would benefit greatly from utilizing procedures such as EEG, fMRI, MRI and MEG to better understand how neurological and psychosocial development interact to explain adolescents decisions to engage in variety of health risk behaviors, including physical activity and sedentary behavior. Finally, it should be recognized that the results of the correlational analyses represent associations among variables and should not be interpreted as cause and effect.

Perspectives

In line with the recommendations of Sherar et al., (2010) the present study examined concurrent and prospective associations among biological maturation, body composition, PA, and sedentary behavior, using a series of objective measures. Whereas maturation was found to be inversely associated with mean accelerometer CPM, LPA, and MVPA, and positively associated with time spent sedentary, in males at 11 and 13 years of age; evidence linking maturation with concurrent levels of PA and sedentary behavior in females at 11 and 13 years was limited. Contrary to expectations, biological maturation and percentage fat free mass at age 11 did not predict any indices of PA or sedentary behavior at age 13, in either sex. Collectively these results suggest that the impact of biological maturation on PA and sedentary behavior is either smaller or more complex than previously assumed. As noted, future research needs to be interdisciplinary in nature and include factors that might mediate or moderate the effects of maturation on PA and sedentary behavior, such as perceptions of 
the physical self-, parental and peer-support, and indicators of adverse social and environmental contexts. 


\section{References}

1. Bradley CB, McMurray RG, Harrell JS, Deng SB. Changes in common activities of 3rd through 10th graders: the CHIC Study. Med Sci Sports Exerc. 2000: 32: 20712078.

2. Byers JA. The biology of human play. Child Dev. 1998: 69: 599-600.

3. Caspi A, Moffitt TE. Individual differences are accentuated during periods of social change: The sample case of girls at puberty. J Pers Soc Psychol. 1991: 61: 157-168.

4. Child Growth Foundation. Boys and girls growth charts 2 - 18 years. London: Child Growth Foundation, 2005.

5. Cole TJ. Growth charts for both cross-sectional and longitudinal data. Stat Med. 1994: 13: $2477-2492$.

6. Cumming SP, Riddoch C. Physical activity, fitness and children's health: current concepts. In: Armstrong N, Van Mechelen W, eds. Paediatric Exercise Science and Medicine: Oxford University Press, 2009:327-338.

7. Cumming SP, Sherar LB, Hunter Smart JE, Machado Rodrigues AM, Standage M, Gillison FB, Malina RM. Differences in the physical activity, physical self-concept, and health-related quality of life between adolescent females at the extremes of the biological maturity continuum. J Early Adolesc. 2012: 32: 267-290.

8. Cumming SP, Sherar LB, Pindus DM, Coelho e Silva MJ, Malina RM, Jardine PR. A biocultural model of maturity-associated variance in adolescent physical activity. IntRev Sport ExercPsychol. 2012: 5: 23-43.

9. Cumming SP, Standage M, Loney T, Gammon C, Neville H, Sherar LB, Malina RM. The mediating role of physical self-concept on relations between biological maturity status and physical activity in adolescent females. J Adolesc. 2011: 34: 465-473. 
10. Davison KK, Werder JL, Trost SG, Baker BL, Birch LL. Why are early maturing girls less active? Links between pubertal development, psychological well-being, and physical activity among girls at ages 11 and 13. Soc Sci Med. 2007: 64: 2391-2404.

11. Dollman J, Norton K, Norton L. Evidence for secular trends in children's physical activity behaviour. Brit J Sport Med. 2005: 39: 892-897.

12. Eisenmann JC, Wickel EE. Biology of physical activity in children: Revisited. Ped Exerc Sci. 2009: 21: 257-272.

13. Epstein L, Valoski AM, Kalarchian MA, McCurley J. Do children lose and maintain weight easier than adults? A comparison of child and parent weight changes from six months to ten years. Obesity Res. 1995: 3: 411-417.

14. Field A. Discovering statistics using SPSS. London: Sage, Publications 2005.

15. Ge X, Natsuaki MN, Jin R, Biehl M. A contextual amplification hypothesis. Pubertal timing and girls' problem behaviors. In: Kerr M, Stattin H, Engels RCME, Overbeek G, Andershed AK, eds. Understanding girls'probelm behavior: How girls' delinquency develops in the context of maturity and health, co-occuring problems and relationships. London: Wiley, 2011:11-29.

16. Gebremariam M, Bergh I, Andersen L, Ommundsen Y, Bjelland M, Lien N. Stability and change in potential correlates of physical activity and association with pubertal status among Norwegian children in the transition between childhood and adolescence. Int J Behav Nutr Phy. 2012: 9.

17. Hearst MO, Patnode CD, Sirard JR, Farbakhsh K, Lytle LA. Multilevel predictors of adolescent physical activity: a longitudinal analysis. Int J Behav Nutr Phy. 2012: 9.

18. Hensley WE. The measurement of height. Adolescence. 1998: 33: 629-635.

19. Himes JH, Roche AF. Reported Versus Measured Adult Statures. Am J Phys Anthropol. 1982: 58: 335-341. 
20. Hunter Smart JE, Cumming SP, Sherar LB, Standage M, Neville H, Malina RM. Maturity associated variance in physical activity and health-related quality of life in adolescent females. A mediated effects model. J Phys Act Health. 2012: 9: 86-95.

21. Katzmarzyk PT, Shen W, Baxter-Jones A, Bell JD, Butte NF, Demerath EW, Gilsanz V, Goran MI, Hirschler V, Hu HH, Maffeis C, Malina RM, Muller MJ, Pietrobelli A, Wells JCK. Adiposity in children and adolescents: correlates and clinical consequences of fat stored in specific body depots. Pediatr Obes. 2012: 7: E42-E61.

22. Khamis HJ, Roche AF. Predicting adult height without using skeletal age: The Khamis-Roche method. Pediatrics. 1994: 94: 504-507 (Pediatrics, 595, 457, 1995 for the corrected version of the tables).

23. Knowles A, Niven AG, Fawkner SG, Henretty JM. A longitudinal examination of the influence of maturation on physical selfperceptions and the relationship with physical activity in early adolescent girls. J Adolesc. 2009: 32: 555-566.

24. Malina RM. Skeletal Age and Age Verification in Youth Sport. Sports Med. 2011: 41: 925-947.

25. Malina RM, Bouchard C, Bar-Or O. Growth Maturation and Physical Activity. Champaign, IL: Human Kinetics 2004.

26. Malina RM, Dompier TP, Powell JW, Barron MJ, Moore MT. Validation of a Noninvasive maturity estimate relative to skeletal age in youth football players. Clin $J$ Sport Med. 2007: 17: 362-368.

27. Malina RM, Morano PJ, Barron M, Miller SJ, Cumming SP. Growth status and estimated growth rate of youth football players: A community-based study. Clin J Sport Med. 2005: 15: 125-132. 
28. Malina RM, Morano PJ, Barron MA, Miller SJ, Cumming SP, Kontos AP. Incidence and player risk factors for iInjury in youth football. Clinical J Sport Med. 2006: 3: 214-222.

29. Mattocks C, Leary S, Ness A, Deere K, Saunders J, Tilling K, Kirkby J, Blair SN, Riddoch C. Calibration of an accelerometer during free-living activities in children. Int J Pediatr Obes. 2007: 2: 218-226.

30. Nelson, MC, Neumark-Stzainer D, Hannan PJ, Sirard JR, Story M. Longitduinal and secular trends in physical activity and sedentary behavior during adolescence. Pediatrics. 2006: 118: 1627-1634

31. Niven AG, Fawkner SG, Knowles A, Stephenson C. Maturational differences in physical self-perceptions and the relationship with physical activity in early adolescent girls. Ped Exerc Sci. 2007: 19: 472-480.

32. Palta M, Prineas RJ, Berman R, Hannan P. Comparison of Self-Reported and Measured Height and Weight. Am J Epidemiol. 1982: 115: 223-230.

33. Pindus DM, Cumming SP, Sherar LB. Early Maturation and Physical Activity in Adolescent Females: Can "a Little Help from Your Friends" Make a Difference? Ann Behav Med. 2012: 43: S202-S202.

34. Riddoch C, Mattocks C, Deere K, Saunders J, Kirkby J, Tilling K, Blair SN, Ness A. Objective measurement of levels and patterns of physical activity. Arch Dis Child. 2007: 92: 963-969.

35. Riddoch CJ, Leary SD, Ness AR, Blair SN, Deere K, Mattocks C, Griffiths A, Smith GD, Tilling K. Prospective associations between objective measures of physical activity and fat mass in 12-14 year old children: the Avon Longitudinal Study of Parents and Children (ALSPAC). Brit Med J. 2009: 339. 
36. Romon M, Lafay L, Bresson JL, Oppert JM, Borys JM, Kettaneh A, Charles MA. Relationships between physical activity and plasma leptin levels in healthy children: the Fleurbaix-Laventie Ville Sante II Study. Int J Obesity. 2004: 28: 1227-1232.

37. Sherar LB, Cumming SP, Eisenmann JC, Baxter-Jones ADG, Malina RM. Adolescent biological maturity and physical activity: Biology meets behaviour Ped Exerc Sci. 2010: 22: 332-349.

38. Sherar LB, Gyurcsik NC, Humbert ML, Dyck RF, Fowler-Kerry S, Baxter-Jones ADG. Activity and Barriers in Girls (8-16 yr) Based on Grade and Maturity Status. Med Sci Sports Exerc. 2009: 41: 87-95.

39. Smart JEH, Cumming SP, Sherar LB, Standage M, Neville H, Malina RM. Maturity Associated Variance in Physical Activity and Health-Related Quality of Life in Adolescent Females: A Mediated Effects Model. J Phys Act Health. 2012: 9: 86-95.

40. van Jaarsveld CHM, Fidler JA, Simon AE, Wardle J. Persistent impact of pubertal timing on trends in smoking, food choice, activity, and stress in adolescence. Psychosom Med. 2007: 69: 798-806.

41. Wickel EE, Eisenmann JC. Maturity-related differences in physical activity among 13-14- year old adolescents. Ped Exerc Sci. 2007: 19: 384-392.

42. Zitouni D, Guinhouya BC. Maturity negates the gender-related difference in physical activity among youth. Is this equally justified whatever the accelerometer cut-off point used? J Sci Med Sport. 2012: 15: 327-333. 


\section{Table 1.}

Mean (SD) values of the participants' physical characteristics, physical activity levels and sedentary behavior at 11 and 13 years of age, by sex. 


\begin{tabular}{|c|c|c|c|c|}
\hline & \multicolumn{2}{|c|}{$\begin{array}{c}\text { Males } \\
(n=671)\end{array}$} & \multicolumn{2}{|c|}{$\begin{array}{l}\text { Females } \\
(n=680)\end{array}$} \\
\hline & 11 years & 13 years & 11 years & 13 years \\
\hline Chronological Age & $11.7(.1)$ & $13.8(.1)$ & $11.7(.1)$ & $13.8(.1)$ \\
\hline Height (cm) & $149.5(6.9)$ & $164.4(8.7)$ & $150.9(6.9)$ & $161.9(6.2)$ \\
\hline Weight (kg) & $41.8(9.2)$ & $53.5(11.2)$ & $43.2(9.2)$ & $53.5(9.8)$ \\
\hline BMI $\left(\mathrm{kg} / \mathrm{m}^{2}\right)$ & $18.6(3.1)$ & $19.7(3.1)$ & $18.9(3.1)$ & $20.4(3.3)$ \\
\hline Total Body Fat (\%) & $22.7(9.2)$ & $19.1(9.3)$ & $27.6(8.1)$ & $28.8(8.0)$ \\
\hline Trunk Fat (\%) & $9.1(4.6)$ & $7.9(4.6)$ & $11.7(4.4)$ & $13.0(4.5)$ \\
\hline Lean Mass (\%) & 73.5 (8.9) & $77.0(9.1)$ & $68.8(7.8)$ & $67.2(7.8)$ \\
\hline Predicted adult stature & $178.6(6.3)$ & $178.7(6.6)$ & $165.8(4.6)$ & $165.9(5.3)$ \\
\hline \% Predicted Adult Stature & $83.7(1.9)$ & $91.9(2.4)$ & $91.0(2.9)$ & $97.6(1.3)$ \\
\hline Daily monitor wear time & $790.2(45.5)$ & 794.7 (53.9) & $780.3(44.9)$ & $789.2(53.2)$ \\
\hline Counts/min 7-days & $645.8(177)$ & $592.0(191)$ & $544.7(148)$ & $485.4(147)$ \\
\hline Counts/min weekdays & $654.5(187)$ & $603.3(196)$ & $546.8(152)$ & $489.6(154)$ \\
\hline Counts/min weekend days & $618.8(239)$ & $562.9(293)$ & $534.3(201)$ & $470.5(221)$ \\
\hline MVPA (min/day) 7-days & $27.5(16.6)$ & $29.1(18.1)$ & $18.2(11.4)$ & $20.0(14.7)$ \\
\hline $\begin{array}{l}\text { MVPA (min/day). } \\
\text { (weekdays) }\end{array}$ & $29.2(18.2)$ & 31.1 (19.8) & $19.2(12.6)$ & $21.7(16.4)$ \\
\hline $\begin{array}{l}\text { MVPA (min/day). (weekend } \\
\text { days) }\end{array}$ & $22.9(19.8)$ & $23.9(25.0)$ & $15.2(14.2)$ & $15.5(17.3)$ \\
\hline Light PA (min/day). & 335.1 (56.7) & $290.5(57.8)$ & 32.12 (57.6) & $269.6(50.7)$ \\
\hline Sedentary (min/day). & $427.6(63.4)$ & $475.1(67.2)$ & $440.9(63.6)$ & $499.6(62.5)$ \\
\hline
\end{tabular}


Table 2

Correlations between biological maturity status and physical characteristics and physical activity by sex and age.

\begin{tabular}{|c|c|c|c|c|}
\hline & \multicolumn{2}{|c|}{$\begin{array}{l}\text { Males } \\
\mathrm{n}=671\end{array}$} & \multicolumn{2}{|c|}{$\begin{array}{l}\text { Females } \\
n=680\end{array}$} \\
\hline & 11 years & 13 years & 11 years & 13 years \\
\hline Percentage Fat Mass & $.41^{\mathrm{C}}$ & -.05 & $.46^{\mathrm{c}}$ & $.55^{\mathrm{c}}$ \\
\hline Percentage Trunk Fat & $.41^{\mathrm{c}}$ & .03 & $.49^{\mathrm{c}}$ & $.57^{\mathrm{c}}$ \\
\hline Percentage Lean Mass & $-.41^{c}$ & .05 & $-.47^{\mathrm{c}}$ & $-.56^{\mathrm{c}}$ \\
\hline Counts/min 7-days & $-.14^{\mathrm{c}}$ & $-.09^{b}$ & $-.07^{\mathrm{a}}$ & .05 \\
\hline Counts/min Weekday & $-.12^{b}$ & $-.07^{\mathrm{a}}$ & $-.08^{\mathrm{a}}$ & .04 \\
\hline Counts/min Weekend days & $-.14^{\mathrm{C}}$ & $-.09^{\mathrm{a}}$ & -.05 & .04 \\
\hline MVPA (min/day). 7-days* & $-.11^{\mathrm{b}}$ & -.04 & -.04 & .04 \\
\hline MVPA (min/day). Weekday* & $-.09^{b}$ & -.03 & -.04 & .03 \\
\hline MVPA (min/day). Weekend & $.10^{\mathrm{b}}$ & -.03 & -.05 & .05 \\
\hline days* & & & & \\
\hline Light PA (min/day). * & $-.08^{\mathrm{a}}$ & $-.10^{\mathrm{b}}$ & -.05 & -.01 \\
\hline Sedentary (min/day). * & $.10^{\mathrm{b}}$ & $.10^{\mathrm{b}}$ & .05 & .00 \\
\hline
\end{tabular}

* Correlations controlled for mean monitor wear time per valid day. $\mathrm{a}=\mathrm{p}<.05 ; \mathrm{b}=\mathrm{p}<.01 ; \mathrm{c}=\mathrm{p}<.001$ 


\section{Table 3}

Multilevel models (final) explaining counts per minute and time spent sedentary and in moderate-to-vigorous and light physical activity at 13 years of age, in males. 
Multilevel Models

$\beta$

SE

$\mathrm{p}$

95\%CI

Counts/min at 13 (Model 2)

Counts/min at 11

.50

.04

.00

$.42, .57$

Total body fat \% at 11

$-.14$

.80

.86

$-1.72,1.43$

Biological maturation at 11

1.20

3.82

.75

$-6.31,8.70$

$\underline{\text { MVPA at } 13 \text { (Model 2) }}$

Wear time at 11

$-.05$

.01

.00

$-.07,-.02$

Wear time at 13

.08

.01

.00

$.05, .10$

MVPA at 11

.47

.04

.00

$.40, .55$

Total Body Fat \% at 11

$-.06$

.08

.41

$-.21, .09$

Biological Maturation at 11

.21

.36

.56

$-.50, .92$

\section{Light PA at 13 (Model 1)}

Mean wear time at 11

Mean wear time at 13

Light PA at 11

Total Body Fat \% at 11

Biological Maturation at 11

\section{$-.23$}

.37

.50

$-.07$

.07
.04

.03

.03

.22

1.07
.00

.00

.00

.76

.95
$-.31,-.14$

$.29, .43$

$.43, .56$

$-.49, .36$

$-2.02,2.17$

$\underline{\text { Time sedentary at } 13 \text { (Model 1) }}$

Mean wear time at 11

$-.23$

.05

.00

$-.33,-.14$ 


$\begin{array}{lcccc}\text { Mean wear time at } 13 & .56 & .04 & .00 & .48, .64 \\ \text { Time sedentary at } 11 & .51 & .03 & .00 & .44, .58 \\ \text { Total Body Fat \% at } 11 & .10 & .24 & .69 & -.38, .58 \\ \text { Biological Maturation at } 11 & -.29 & 1.19 & .81 & -2.63,2.05\end{array}$


Table 4

Multilevel models (final) explaining mean counts per minute and time spent sedentary and in moderate-to-vigorous and light physical activity at 13 years of age, in females. 
Multilevel Models

$\beta$

SE

p

95\%CI

\section{Counts/min at 13 (Model 1)}

Counts/min at 11

Total body fat \% at 11

Biological maturation at 11
50

$-.09$

2.64
.04

.70

2.02
.00

.90

.19

$$
.42, .57
$$

$-1.34,6.60$

\section{$\underline{\text { MVPA at } 13 \text { (Model 1) }}$}

Wear time at 11

Wear time at 13

MVPA at 11

Total body fat \% at 11

Biological maturation at 11

$$
-.02
$$

.05

.50

.07

.21
.01

.01

.05

.07

.20

\section{.23}

.00

.00

.37

.29
$-.04, .01$

.03, .07

$.41, .59$

$-.08, .21$

$-.18, .61$

\section{$\underline{\text { Light PA at } 13 \text { (Model 1) }}$}

Wear time at 11

$-.17$

.04

.00

$-.25,-.10$

Wear Time at 13

.29

.03

.00

$.23, .36$

Light PA at 11

.42

.03

.00

$.36, .48$

Total body fat $\%$ at 11

$-.31$

.23

.18

$-.75, .14$

Biological maturation at 11

$-.57$

.64

.37

$-1.83, .68$

\section{$\underline{\text { Time sedentary at } 13 \text { (Model 1) }}$}

Wear time at 11

Wear Time at 13

Time sedentary at 11
$-.23$

.66

.42
.04

.03

.03
.00

$-.32,-.15$

.00

.59, .72

.00

.36, .48 
Total body fat $\%$ at 11

.26

.24

.28

$-.21, .73$

Biological maturation at 11

.34

.67

.61

$-.99,1.67$ 
Figure 1. Khamis Roche equation for predicting adult stature

$$
\text { predicted adult stature }=\beta 0+\beta 1 \text { stature }+\beta 2 \text { weight }+\beta 3 \text { midparent stature }
$$

Where $\beta 0$ is a sex and age specific intercept and $\beta 1, \beta 2, \& \beta 3$ are sex and age specific coefficients which stature, weight and midparent height should be multiplied. 
Figure 2. Equations for adjusting self-reported heights in adults

$$
\begin{gathered}
\text { male adult height }=2.316+(0.955 \times \text { height }) \\
\text { female adult height }=2.803+(0.953 \times \text { height })
\end{gathered}
$$

Note. The equations are not metric. Height is reported in inches. 


\section{Acknowledgements}

We are extremely grateful to all the families who took part in this study, the midwives for their help in recruiting them, and the whole ALSPAC team, which includes interviewers, computer and laboratory technicians, clerical workers, research scientists, volunteers, managers, receptionists and nurses. The UK Medical research Council and the Wellcome Trust Grant (\#092731) and the University of Bristol provide core support for ALSPAC. This publication is the work of the named authors and they serve as guarantors for the contents of this paper. 